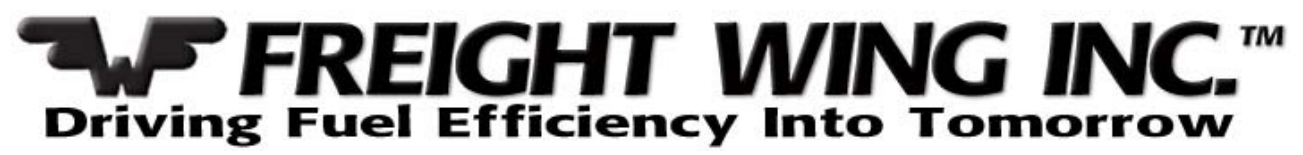

Final Report

\title{
Freight Wing Trailer Aerodynamics
}

October 10, 2004

\author{
Freight Wing Incorporated \\ 520 East Lake Sammamish Parkway, NE \\ Sammamish, WA 98074 \\ Sean@Freightwing.com \\ 425-996-0224
}

Award Number: DE-FG36-03G013173

Contact:

Sean Graham (Principal Investigator) sean@freightwing.com 206-769-7880

Patrick Bigatel pat@freightwing.com 425-417-9984

Project Team:

Gibson Asuquo (DOE HQ Program Manager)

Aaron Moeller (DOE Field Project Officer) 


\section{Executive Summary}

Freight Wing Incorporated utilized the opportunity presented by this DOE category one Inventions and Innovations grant to successfully research, develop, test, patent, market, and sell innovative fuel and emissions saving aerodynamic attachments for the trucking industry.

A great deal of past scientific research has demonstrated that streamlining box shaped semi-trailers can significantly reduce a truck's fuel consumption. However, significant design challenges have prevented past concepts from meeting industry needs. Market research early in this project revealed the demands of truck fleet operators regarding aerodynamic attachments. Products must not only save fuel, but cannot interfere with the operation of the truck, require significant maintenance, add significant weight, and must be extremely durable. Furthermore, SAE/TMC J1321 tests performed by a respected independent laboratory are necessary for large fleets to even consider purchase. Freight Wing used this information to create a system of three practical aerodynamic attachments for the front, rear and undercarriage of standard semi trailers. SAE/TMC J1321 Type II tests preformed by the Transportation Research Center (TRC) demonstrated a 7\% improvement to fuel economy with all three products.

Positive test results generated interest from fleet contacts such as Transport America, who formed a partnership with Freight Wing to test fifteen fairings in everyday operations. Satisfied with the performance of the products, Transport America has agreed to expand the project to 100 trailers. With patents applied for on all three designs, Freight Wing made its market launch with advertising and a professional PR campaign. Several articles in large publications were generated, which have lead to many strong leads and our initial sale.

If Freight Wing is successful in its continued efforts to gain market penetration, the energy and environmental savings would be considerable. Each truck outfitted saves approximately 1,100 gallons of fuel every 100,000 miles, which prevents over 12 tons of CO2 from entering the atmosphere. If all applicable trailers used the technology, the country could save approximately 1.8 billion gallons of diesel fuel, 18 million tons of emissions and 3.6 billion dollars annually.

\section{Project Description}

\section{Original Project Goals and Objectives} as follows:

The original project goals and objectives as outlined in our project management plan are

Task 1: Business Formation. Freight Wing will complete the sale of stock in order to obtain private capital funding.

Task 2: Design Optimization. Using the results from CFD tests and continued research, prototype designs will be optimized. 
Task 3: Prototype Development. Full Scale prototypes of the Freight Wing fairing will be developed in association with local fabricators to test and refine the product.

Task 4: Patent Development. Patents will be drafted and submitted in association with our patent attorney, Fred Baehr.

Task 5: Prototype Testing. Prototypes will be tested on semi trucks to measure improvements to fuel efficiency and study operational characteristics.

Task 6: Product Optimization. The results of prototype testing will be utilized to refine the design and create improved prototypes for further testing ultimately resulting in a final design for production and marketing.

Task 7: Business Development. Throughout the project, Freight Wing Inc. will build the business foundation necessary to produce the product and market the optimized designs.

Task 8: Market Research. Freight Wing Inc. will conduct detailed market research to aid in product design and determine how to market its products most effectively.

Task 9: Report Submission. Quarterly reports and a comprehensive final report will be submitted to the DOE as requested.

\section{Variance From Original Goals and Objectives}

Freight Wing Inc. successfully completed all of its original goals and objectives for this project. However, the means by which we completed the project differed significantly from what was expected.

Original project goals focused on the development of a "rear fairing" or aerodynamic attachment for the box like end of semi-trailers. The initial design changed considerably as early market research revealed the industry demands that such products be maintenance free, lightweight yet durable, as inexpensive as possible, and free of any operational changes or inconvenience to drivers. We therefore compromised some of the fuel saving potential of the rear fairing to pursue a simpler design. Computational fluid dynamics tests performed by FLUENT Inc. demonstrated other areas on the trailer that could be streamlined to further improve aerodynamics and make up for the loss. Consequently, two other products were conceived: a "gap" fairing for the front of the trailer and a "belly" fairing for the undercarriage. All three fairings had several generations of prototypes constructed by our manufacturing partner, ASAP Metal Fabricators.

We had originally planned on testing the fuel saving ability of the products with a fleet partner. However, the fleets we talked to about design issues, as well as the Freightliner LLC engineers that helped us with our first operations/road test, made it clear that SAE J1321 type II standardized tests performed by a respected facility were absolutely necessary to gain market acceptance. For example, a letter from Schneider National (Americas largest private carrier) is attached (see supplemental information figure 11) which informed us that they do not consider any product without SAE/TMC test results. Fleet owners are very skeptical of fuel savings products because they are often approached by companies marketing ineffective products with exaggerated claims and questionable "test results". As we learned first hand, it is also quite 
difficult to achieve accurate test results without the standardized procedure and control of the J1321 test. For our first attempt at a fuel economy test, we hired a local fleet to test the rear fairing on one truck over a three day period. The tests indicated the device was saving $6 \%$ of the trucks fuel. In reality, much of that "savings" was due to testing the truck without the fairing in the morning and with the fairing in the afternoon- when the truck was running warmer and more efficiently. This is why SAE J1321 tests mandate that a second control truck be employed at all times. Similar problems have been experienced by other DOE funded aerodynamic truck projects. For example, the "Pneumatic Heavy Vehicle" project conducted by GTRI reported a 13\% efficiency gain during non-standardized tests in the April 2002 Working Group Meeting on Heavy Vehicle Aerodynamic Drag (UCRL-ID-149855). However, SAE J1321 testing at the TRC later demonstrated only a $3 \%$ to $4 \%$ improvement. Fortunately, the addition of significant private equity funding to Freight Wing enabled us to cover the large expense of hiring the TRC to complete SAE J1321 type II tests on all our products in July 2004.

We were, at first, disappointed by the $7 \%$ reduction in fuel use demonstrated by our products during J1321 tests at the TRC, as this did fall short of our original expectations. However, TRC engineers told us that this was the best performance they had ever seen, and they even ran a second baseline test to make sure the results were accurate. As it turns out, $7 \%$ appears to be the best published SAE/TMC J1321 test result for an aerodynamic semitrailer by a significant margin. The new product designs are also much less expensive to produce than our original concept, and thereby produce a better return on investment than we originally expected.

Since the SAE testing, we have generated significant interest from fleets. This interest has enabled us to greatly outpace our anticipated project schedule and accomplish many goals we did not think possible within its timeframe including: an operations test with a major fleet, our market launch, initial production and initial sales.

\section{Discussion of Work Performed.}

The work performed to complete our project objectives is summarized by specific tasks in the following discussion.

\section{Task 1: Business Formation.}

Freight Wing Incorporated completed its business formation by forming a C Corporation and offering stock to private equity investors. We exceeded our funding goals by raising $\$ 340,000$ in equity investments, a $\$ 200,000$ loan from a private investor, and a commitment for another $\$ 200,000$ loan should we need it in the future. Our Rule 506, Regulation-D stock offering is now closed and all legal necessities of our business formation have been attended to by our council, the Holland and Knight Law firm.

\section{Task 2: Design Optimization.}

Our design goals for the project were exceeded through the development of three marketable products. The original design for a rear fairing evolved considerably, largely due to the market research completed in Task 8 . The new rear fairing concept is vastly less complex than the original, requiring no power or mechanisms to convert from its deployed mode to its stored mode for loading/unloading. This greatly reduces expected manufacturing costs, maintenance, and weight, while enhancing durability (issues that are of primary concern to the 
industry). A decrease in expected performance was compensated for by the development of the gap and belly fairings. The gap fairing was designed to prevent airflow from hitting the front face of the trailer directly. It is the first gap fairing designed specifically for use with modern aerodynamic cabs by shielding only the top and sides of the front face. The belly fairing was designed to shield the trailers underside and tandem axle from drag inducing airflow and reduce suction drag on the rear of the tractor. The functional, lightweight, modular design is constructed from the same cost effective materials as our other products and is easily mounted on any standard trailer.

\section{Task 3: Prototype Development.}

Freight Wing first investigated many potential prototype development and manufacturing resources. We eventually partnered with ASAP Metal Fabricators and completed two rear fairing prototypes of different material thicknesses to compare their operational characteristics. The first generation gap fairing prototype was completed next, which revealed some gaps in the sheet metal seams that required modification. A new rear fairing prototype was also completed that incorporated new design features which solved the minor issues raised by the first prototypes. A belly fairing prototype was completed just in time for our TRC tests along with further improved rear and gap fairings. Fifteen fairings were then completed for our Transport America operational test, five of each design. Our most recent two prototypes of a belly and gap fairing successfully employed thinner materials to reduce weight and cost while maintaining necessary durability. We are completing our first production run of sixty units.

\section{Task 4: Patent Development.}

Once the basic design of the rear fairing was completed, a utility patent application for the design was begun. Freight Wing secured the assistance of a highly experienced patent attorney, Mr. Fred Baehr. The completed rear fairing application was filed on October 30, 2003. A copy of the application, an invention disclosure for the new front fairing design, and later another invention disclosure for the belly fairing, were submitted to Robert J. Fisher (Deputy Chief Counsel, DOE Chicago Operations Office). A patent application for the front fairing was then drafted and submitted August 31, 2004. The belly fairing followed on Sept 30, 2004. Copies of these patents have been submitted to the DOE IP office. A confirmatory license with the DOE has been completed for the rear fairing, and the USPTO examiner told us the application is being accepted. We have not yet received license agreements for the other inventions.

\section{Task 5: Prototype Testing.}

Freight Wing's first full scale prototype tests were completed on the rear fairing in partnership with Freightliner LLC, to demonstrate the functionality and aerodynamic stability of the design. The design met all expectations, proving its ability to maintain a rigid airfoil in all the driving conditions encountered. Tuft strings attached to the airfoil and the back of the truck allowed engineers to visualize airflow. It was therefore possible to measure the degree of curvature that would not induce stall (reversed flow) on the wing surface.

A second road test was completed two months later with a small local fleet to estimate the fuel savings made possible by the rear fairing. Special 13-gallon fuel tanks were attached to the test vehicle such that fuel utilization over an 83 mile loop could be accurately measured by weighing the tanks between test runs. The Freight Wing demonstrated a $6 \%$ decrease in fuel consumption averaged over several test runs made with and without the fairing. However, as 
mentioned in section 2 of this report, our lack of a second full-time control truck as mandated by SAE J1321 tests allowed external factors to corrupt the test results.

Market research had clearly indicated that SAE J1321 standardized tests must be completed by a respected independent organization in order to gain industry acceptance. At the beginning of the project, it appeared that such tests were out of our budget. However, the acquisition of additional private funding in February 2004 enabled us to schedule SAE tests with the automotive industries leading and most respected test facility, The Transportation Research Center (TRC). Each of the three products were evaluated in five separate tests (individually and together) in May, 2004. Two fully loaded, 2004 Freightliner trucks were utilized as baseline and test vehicles on an enclosed circular track. Results indicated that fuel consumption was reduced by $4 \%$ with the belly fairing alone, $6 \%$ with the gap fairing added, and $7 \%$ with all three devices. The TRC test report is available for download on our website and by request.

Freight Wing also initiated an operational test with Transport America, one of the largest 100 fleets in the U.S. All three aerodynamic attachments were outfitted on five new trailers which were inserted in normal fleet operations. Some minor design issues have already been identified and solved through the test, such as the utilization of vibration resistant rivets. Satisfied with the test results thus far, Transport America recently agreed to outfit 100 more trailers through our Clean Air Ads program (see task 7).

\section{Task 6: Product Optimization.}

Freight Wing product optimization began with the market research that steered us away from our original rear fairing design. Initial prototype fabrication also demonstrated the necessity of using standard, cost effective materials and sizing parts for efficient shipping. Initial rear fairing prototype tests led us to make the wings slightly shorter horizontally, because tuft string flow visualization revealed some flow instability and reversed flow on the outer extremities of the wing surface. Sizing the wing down also resulted in considerably reduced manufacturing costs. A similar strategy was then employed to maximize the material utilization of the belly and gap fairings. Modifications were also made to ease and quicken the installation process. Freight Wing products were sufficiently optimized for our operational test with Transport America. Minor changes, including replacing standard rivets with vibration resistant rivets, have occurred since then.

The TRC tests demonstrated that the belly fairing is our most effective product and it has since become the focal point of our product line. The front and rear fairings do not produce enough fuel savings to be effectively marketed on their own. However, when paired with the belly fairing, cost reductions create attractive packages for customers seeking additional fuel savings and/or the aesthetic value of the rear fairing. Currently, the gap fairing is packaged with the belly fairing as the "Freight Wing System". All three products are marketed as the "Freight Wing Full Package". See Freightwing.com for detailed product descriptions.

\section{Task 7: Business Development.}

Freight Wings early business development focused on attracting additional funding from private equity investors. To facilitate this process, international law firm Holland and Knight was employed to attend to our corporate formation and rule 506, Regulation-D stock offering. The initial technical development, prototype fabrication and market research completed in the beginning of this project were integrated in a new business plan. Detailed marketing and sales strategies were also formulated to bring products to market as quickly as possible. The business 
plan was distributed to potential investors and eventually exceeded our funding goals by raising $\$ 340,000$ in equity investments, a $\$ 200,000$ loan from a private investor, and a commitment for another $\$ 200,000$ loan should we need it in the future.

Private Funding enabled us to make the sizable investment necessary to have our products tested at the TRC. The investment soon paid off as the test results generated a great deal of interest within the fleets we were communicating with. Transport America agreed to complete the operational tests of the products on five trailers. As a public company with over 5,000 trailers, Transport America represents an ideal partner. Upon our suggestion, Transport America also used the project to join the EPA's SmartWay Transport Partnership, a voluntary program designed to reduce the environmental impact of the trucking industry. Fleets can use aerodynamic attachments to qualify for the program, which could become very important to our future marketing strategy.

The Transport America partnership has advanced our marketing efforts in many ways. The operational test served as a pilot for our "Clean Air Ads" concept, which has become an integral part of our business development. We believe our products will make a very attractive and cost effective advertising medium when covered with photo quality graphic laminates. We plan on selling advertising on the fairings to independent brands through Clean Air Ads, which could enable us to supply partner fleets with aerodynamic fairings at no cost. A web site was developed for the company, cleanairads.com, and contains more information and images of our demonstration ads. Two test trucks were outfitted with "Drivers Wanted" ads for Transport America, and another two with other examples of creative advertisements. Satisfied with the results of the operational test, Transport America recently agreed to expand the advertising program by 100 trucks. We are beginning to market the opportunity to prospective advertisers and have received positive feedback.

The operational test also gave us the opportunity to generate marketing materials and execute our marketing strategy earlier than anticipated. A professional photographer was hired to create images for use on our websites, sales materials, etc. The Transport America partnership was also featured on a TV program called "Alexander Hague's World Business Review", which was featured on CNBC, BRAVO and other networks in early September. The show represented the launch of a larger PR/media campaign designed to generate awareness in our products. Orchestrated by professional PR consultants, Jose Mallabo and John Chester, our initial press release was well received by the media and resulted in several articles in major industry publications. We were also given the front page of the business section of Seattle's largest paper, the Seattle Post Intelligencer. That articled featured our recent installation of a belly and gap fairing with Gordon Trucking, a major truckload carrier based in Pacific, WA. Gordon is currently evaluating the products for a prospective implementation.

During our product launch and PR campaign, Freight Wing also piloted an advertising program in Transportation Topics magazine, the leading industry periodical. The ad has generated several leads, as well as our first paying customer. In late September a mid sized fleet called LVL Incorporated, based in Arkansas, agreed to purchase two Freight Wing systems at full price. We continue to generate many positive leads as we move forward with our marketing strategy. 


\section{Task 8: Market Research.}

Market Research has played a critical role in the projects development. The initial background work completed before the project began revealed an extremely large potential market suffering from rising fuel costs, and few viable direct competitors. Receiving this DOE grant gave the project credibility by association, which helped us quickly establish relationships in the industry willing to provide feedback. We took our original concept to several fleet managers, industry experts (including Freightliner LLC engineers), and drivers. They identified demanding design criteria that was incorporated in the new designs, and also made us aware of the importance of standardized SAE/TMC J1321 fuel economy tests. Meanwhile, in depth industry, market, and competitive analysis were completed and integrated into our business plan.

The interest in aerodynamic trailers was clearly validated by the positive response our industry contacts had to our test results. Perhaps our most valuable research was the first hand experience of working with Transport America on the operations test, as we gained valuable insight into the operation and needs of a large fleet. As testing continued, research focused on identifying specific fleets for sales. Long-haul, truckload carriers are our primary target as they tend to put the most miles on their trailers, resulting in larger fuel savings. We purchased the North American Truck Fleet Directory from the American Trucking Association (ATA) to assist in this task. This electronic database contains detailed records of over 10,000 trucking fleets which we have been studying to develop a direct marketing strategy.

Later in the project, significant market research was also completed on the outdoor advertising industry to evaluate the prospects of using aerodynamic devices as an advertising medium in Clean Air Ads. We discovered a 2 billion dollar a year outdoor industry that appears open to creative new solutions. Several companies are already engaged in advertising on semi trailers. However, Clean Air Ads would be the fist to offer the distinctive and futuristic look of aerodynamic trailers to draw attention to the attached ads. Freight Wing products would also promote an image of environmental responsibility, as each sponsored truck saves fuel and emissions. Clean Air ads represent "the world's first advertising medium that helps save the environment."

\section{Task 9: Report Submission.}

Three quarterly reports were submitted during the project. This final report, a commercialization report and associated forms were also completed.

\section{Conclusions and Recommendations for Future Work}

Freight Wing has made great progress toward its goal of saving oil, money and emissions through the assistance of the U.S. DOE Inventions and Innovations grant opportunity. In slightly over one year, three patent pending designs for innovative aerodynamic fairings were completed, manufactured, tested and brought to market. With SAE/TMC J1321 proven fuel savings of $7 \%$, durable yet lightweight designs, and a return on investment (ROI) in approximately 100,000 miles, Freight Wing products have already generated significant interest from the trucking industry. Initial sales have commenced, and we are working hard to expand our market presence and energy, oil and emissions saving capabilities. 
Work in the immediate future will concentrate on continued sales, improving sales support and installation capabilities, and expanding sales channels. Marketing development will be ongoing with advertising, direct marketing, press releases, trade show appearances, etc. We also plan on continued research and development to enhance the fuel saving capability of our current products and test new concepts. We hope that the next generation design might be capable of producing a 10\% SAE/TMC J1321 result.

Continued government support could be instrumental to our future success. The market penetration necessary to gain widespread acceptance could accomplished more quickly with additional funding. We therefore plan on submitting another grant proposal when the opportunity becomes available. Widespread acceptance of Freight Wing products would produce a large return on the government's investment through substantial oil, environmental and economic savings. 


\section{Supplemental Information}

\section{Figure 1: The Freight Wing Gap Fairing}

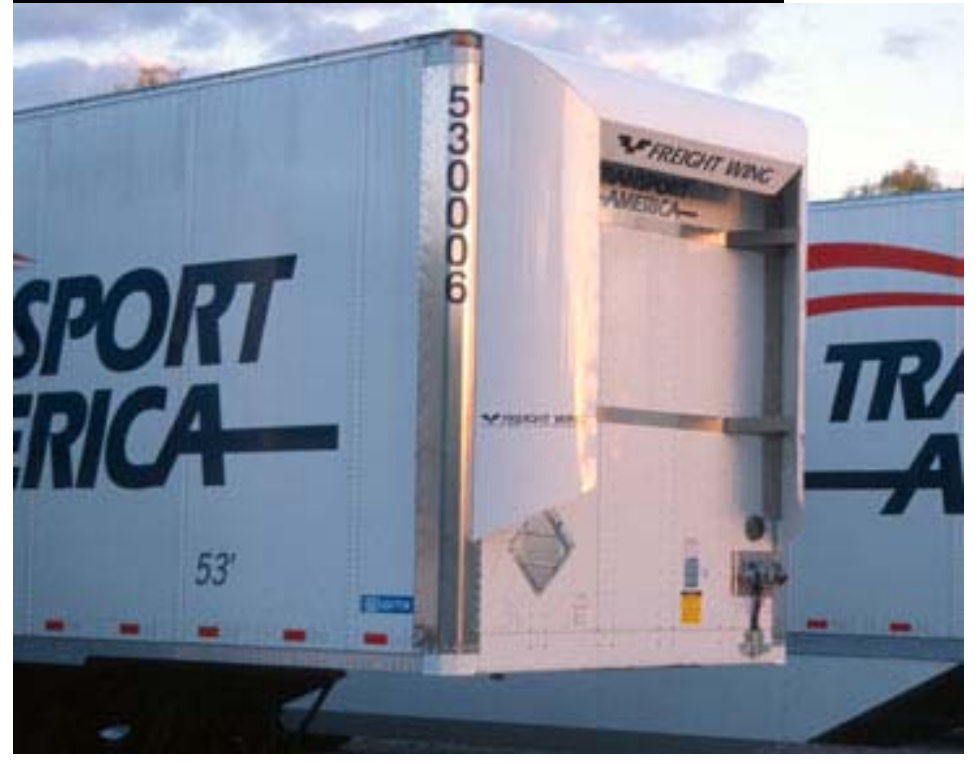

Figure 2: The Freight Wing Belly Fairing
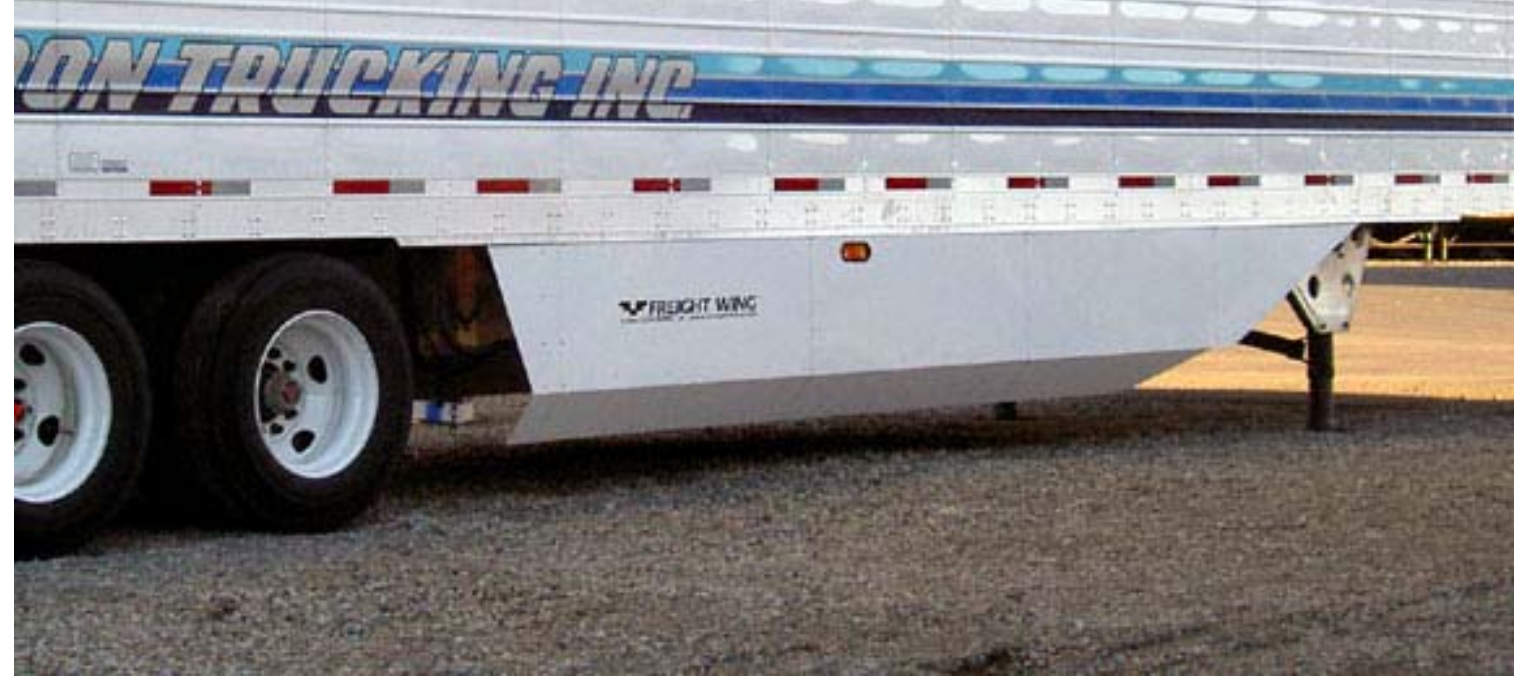


\section{Figure 3: The Freight Wing Rear Fairing}

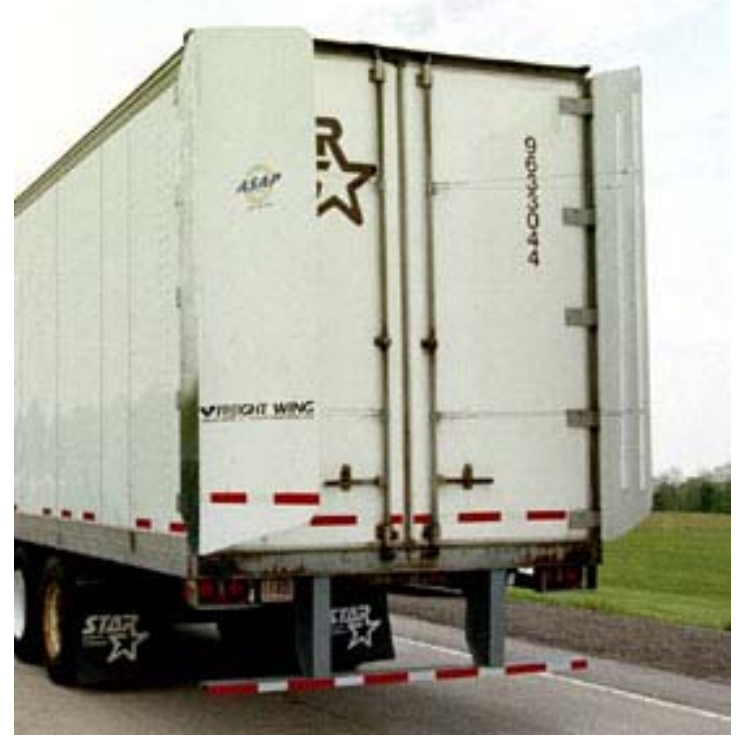

Figure 4: Image of Computer Fluid Dynamics (CFD)Test Truck

Colors represent a spectrum of aerodynamic pressure forces that result in the net drag on the vehicle.

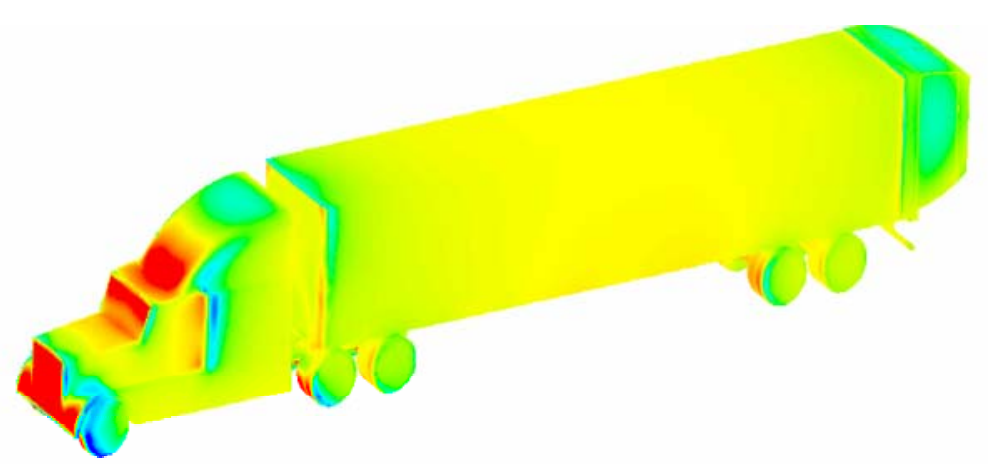


Figure 5: Initial road test vehicle with rear fairing

Tuft strings enabled engineers to visualize air flow.

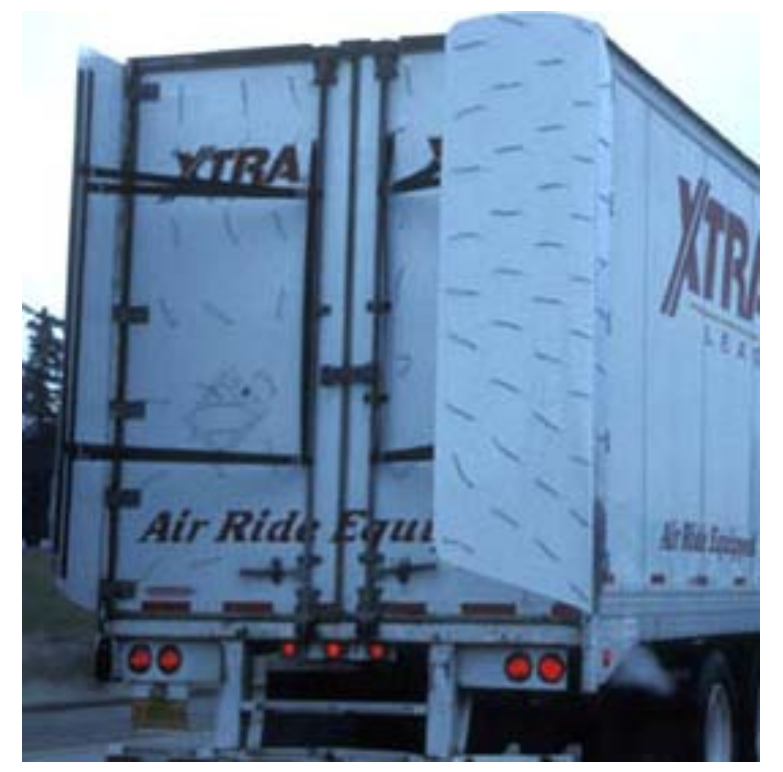

Figure 6: TRC testing

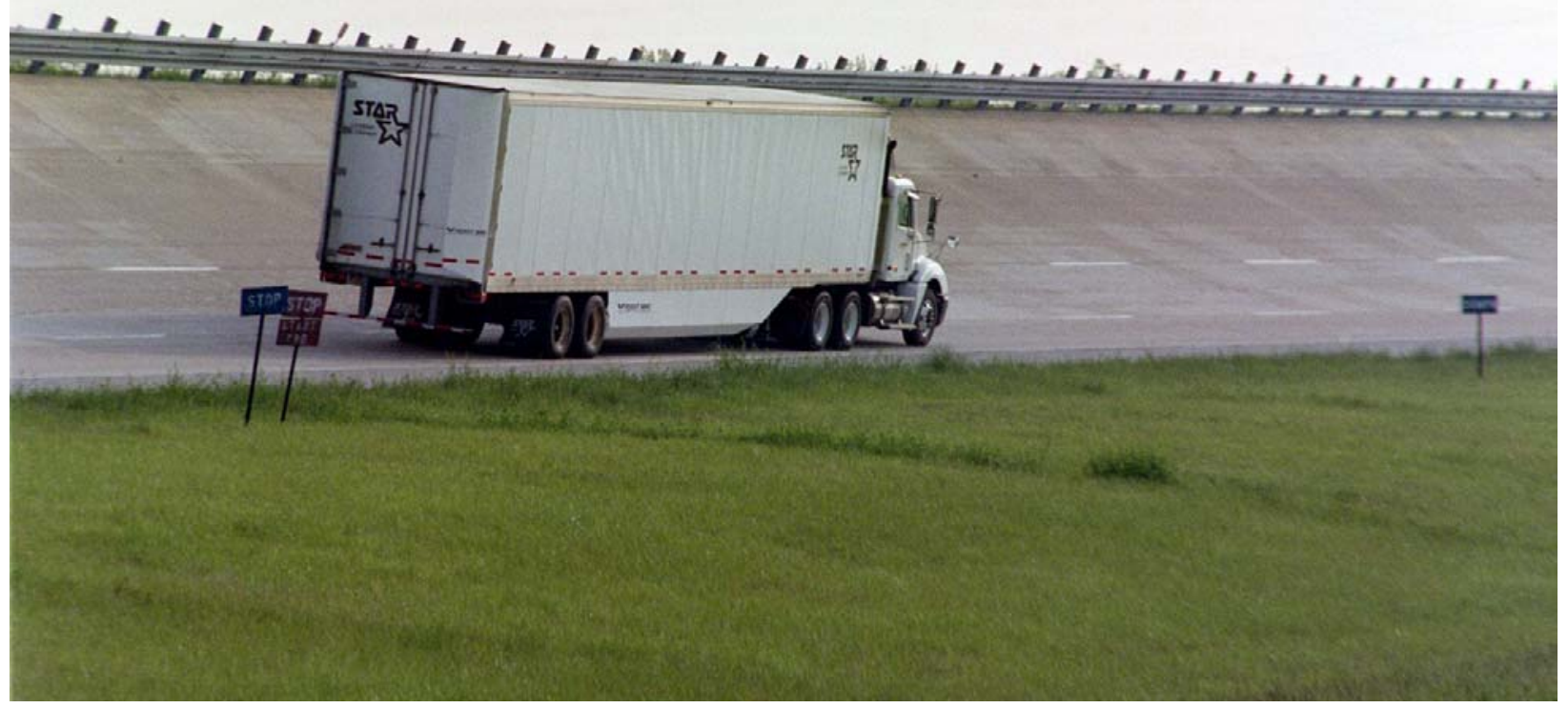


Figure 7: Transport America Truck with All Three Fairings

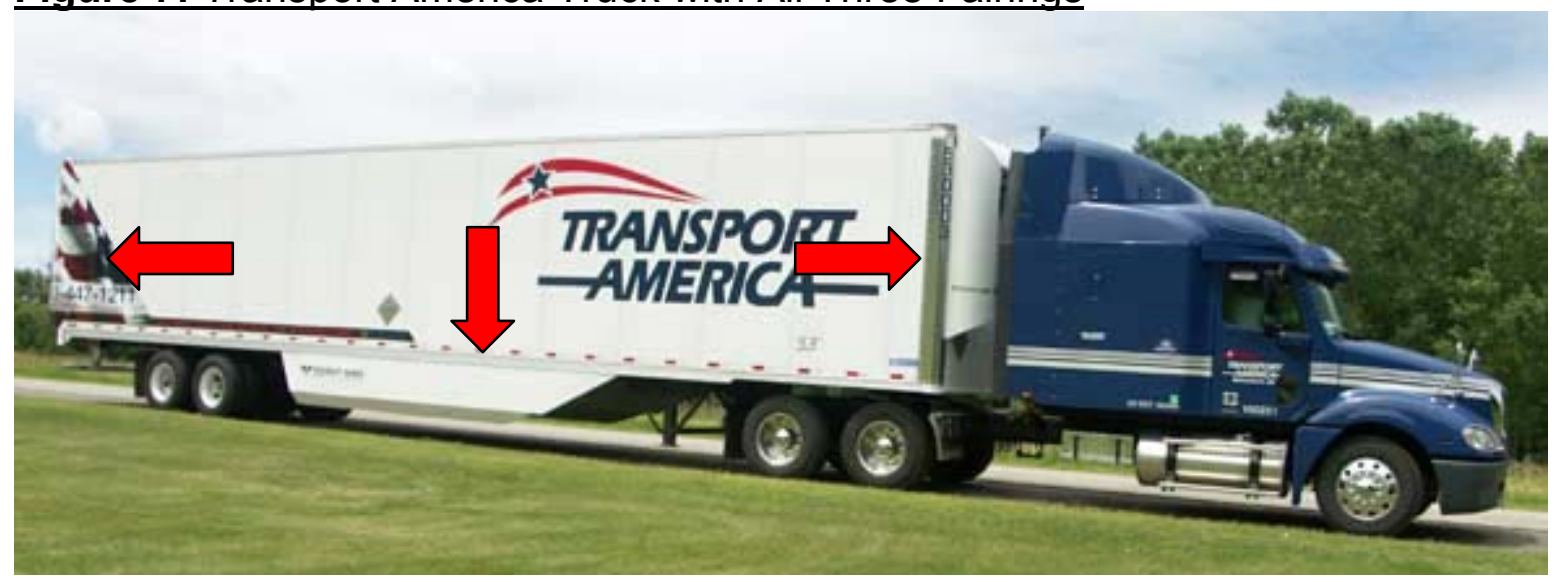

Figure 8: Trailer Lineup in Transport America Yard

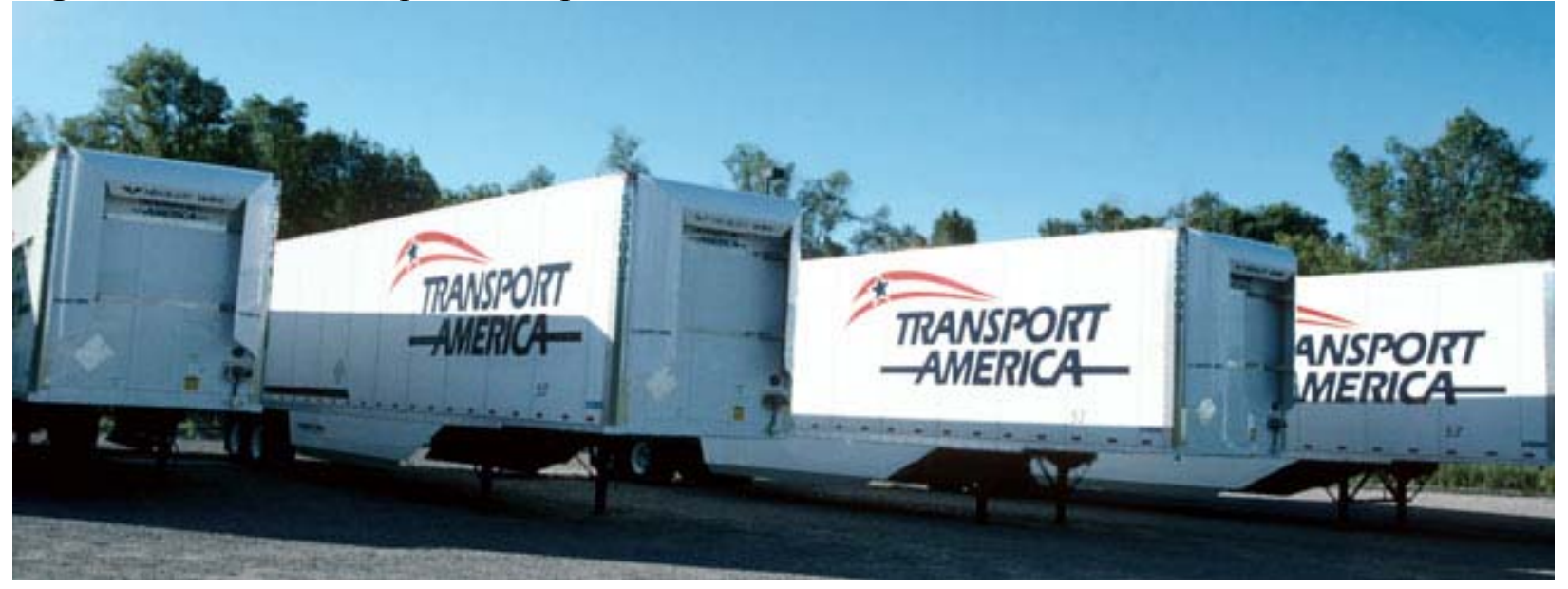


Figure 9: Clean Air Ads on Transport America Trucks

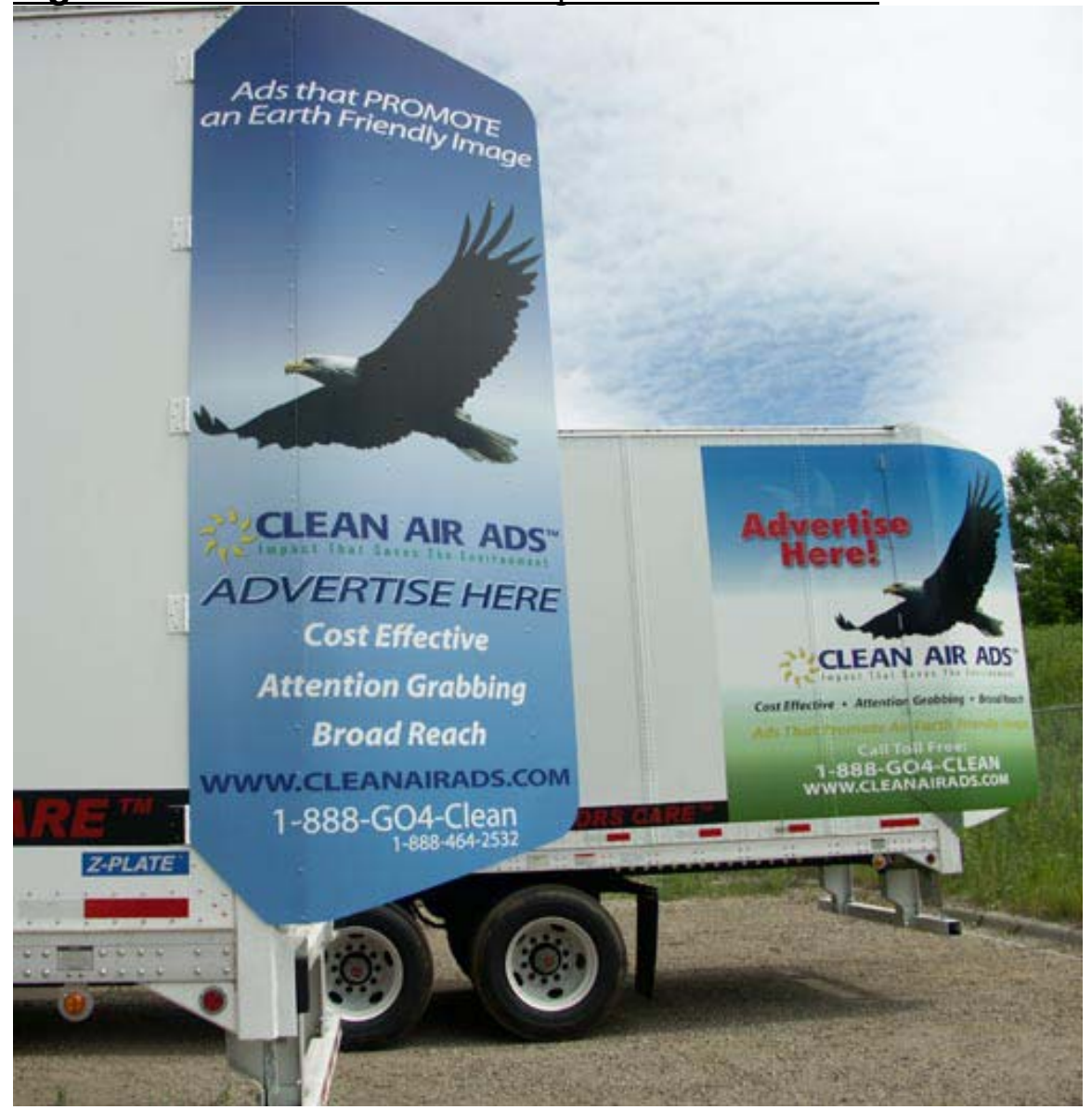

Figure 10: Belly Fairing on Refrigerated Trailer at Gordon Trucking

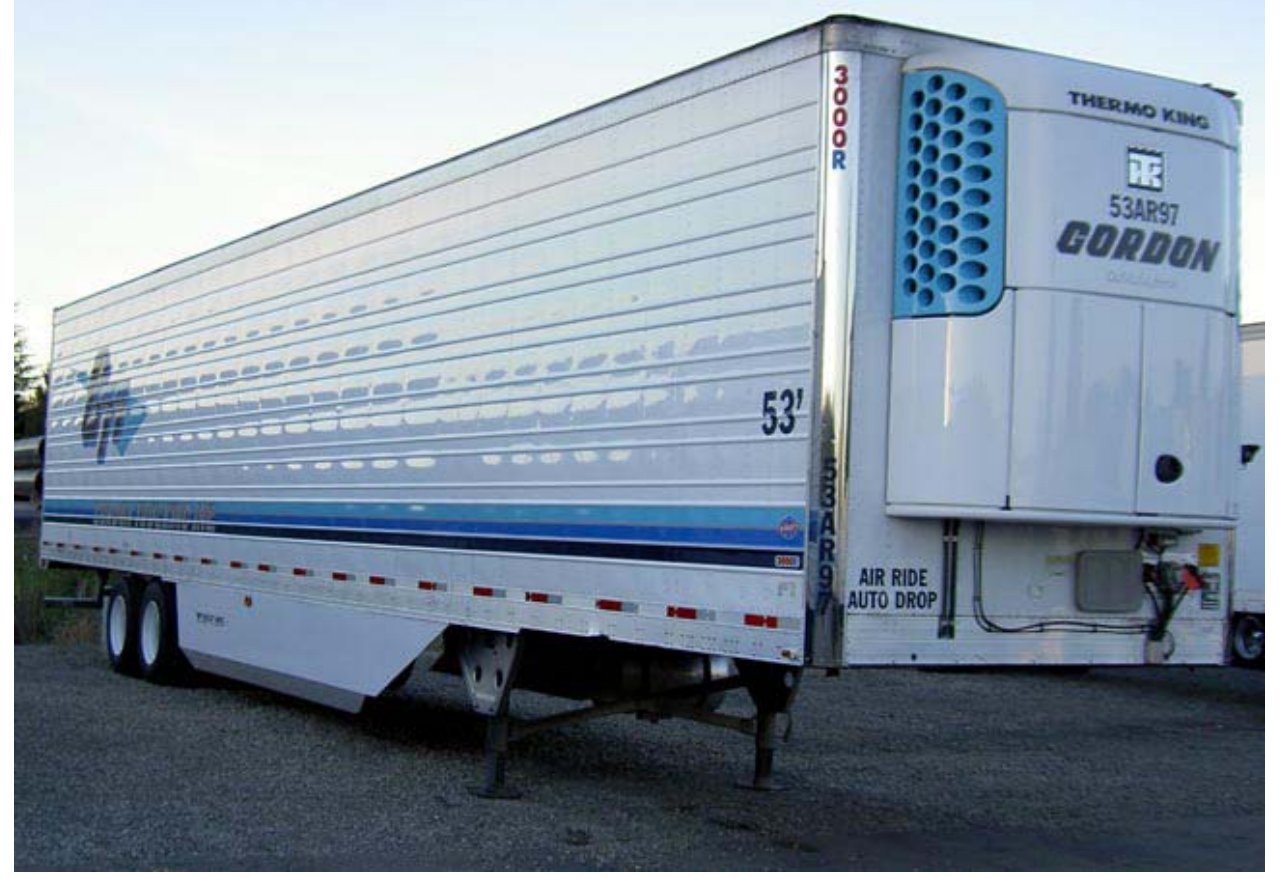




\section{Figure 11: Note Referencing Need for SAE Testing Completed by Freight Wing}

April 13, 2004

Mr. Patrick Bigatel

Chief Executive Officer

Freight Wing Inc.

520 E. Lake Sammamish Parkway NE

Sammanish, WA 98074

Dear Mr. Bigatel:

Thank you for the information on your product. We certainly understand the value of saving fuel. We also know many variables affect field MPG, and there are few companies who can really accurately measure MPG. For Schneider to further consider your product we require that you submit certified SAE Type II (J1321) or Type III (J1526) fuel test data performed on $300 \mathrm{HP}$ or larger diesel powered tractors with 65,000 to $80,000 \mathrm{GVW}$. Also if available, we would like to review EPA transient emissions test data.

Sincerely,

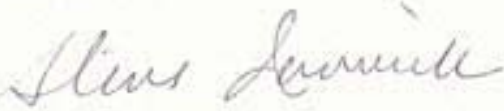

Steve Jarosinski

Manager of Tractor Engineering 


\section{News Coverage}

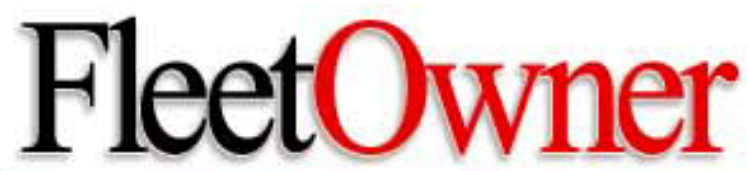

Contact Us | Email Newsletter | Advertisers | Buyer's Guid

\begin{tabular}{|l|}
\hline$>$ MANAGEMENT \\
\hline$>$ EQUIPMENT \\
\hline$>$ INFORMATION TECHNOLOGY \\
\hline$>$ NEWS \\
\hline$>$ SUESCRIBE \\
\hline
\end{tabular}

Search

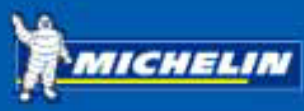

\section{OPEC'S WORST NIGHTMARE.}

Run the Michelin ${ }^{\ominus}$ One tire with aluminum wheels and save a minimum of $4 \%$ on fuel.*

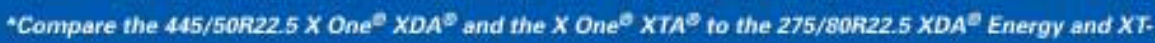

\section{New Trailer Aerodynamic Device}

Sep 16, 2004 3.52 PM

EMAIL THIS ARTICLE

Sammamish, WA-based Freight Wing is launching a new aerodynamic system to help improve the fuel efficiency of trailers. The company developed the device after recieving a grant from the U.S. Department of Energy.

Called the Freight Wing Aerodynamic System, the device streamlines the profile of boxshaped trailers, enabling the tractor's engine to use less fuel, according to Patrick Bigatel, the company's CEO.

The system is composed of three attachments, or fairings, designed to reduce wind drag: one on the front of the trailer, two identical wind deflectors attached to the underside of the trailer, adjacent to its side walls; and a fairing on the end of the trailer to streamline its shape similar to wings on an airplane.

Bigatel said that standardized Society of Automotive Engineers/Technology \& Maintenance Council (SAE/TMC) fuel economy tests conducted on the Freight Wing at the

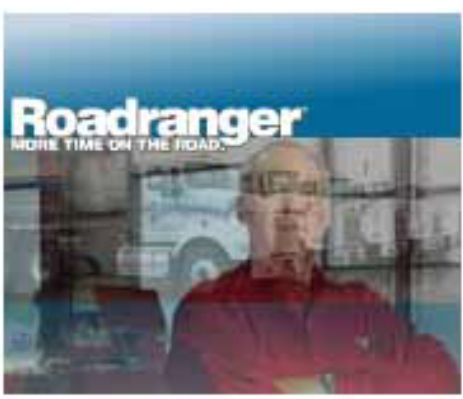
Transportation Research Center proving grounds in Ohio demonstrated a $7 \%$ reduction in the fuel consumption of a fully loaded tractor-trailer. He noted that translates into a savings of up to 1,100 gallons of diesel fuel every 100,000 miles, a distance a typical Class 8 long-haul truck covers in a year.

"Nearly all goods used in this country are transported by large tractor-trailers, making trucking one of the most important sectors in our economy, Bigatel said. "That's why our system represents a tremendous opportunity for delivering cost savings to fleet operators, while reducing U.S. oil consumption and emissions."

Want to use this article? Click here for options! (c) 2004, PRIMEDIA Business Magazines \& Media Inc. 


\section{Links to Additional News Stories}

http://seattlepi.nwsource.com/business/192174 freightwing24.html

http://www.truckinginfo.com/news/news-detail.asp?news id=52663

http://www.layover.com/cgi-bin/portal/printnews.pl/7419.html

http://www.expresstruckingnews.com/KYl/NewsBriefs/body newsbriefs $5 . \mathrm{html}$

\section{Link “World Business Review” Hosted by Gen. Alexander Haig}

http://freightwing.com/worldbusinessreview.htm 


\section{Appendices}

\section{Appendix A \\ Final Task Schedule}

\begin{tabular}{|c|c|c|c|c|c|c|}
\hline \multicolumn{7}{|c|}{ Task Schedule } \\
\hline \multirow[b]{2}{*}{$\begin{array}{c}\text { Task } \\
\text { Number }\end{array}$} & \multirow[b]{2}{*}{ Task Description } & \multicolumn{4}{|c|}{ Task Completion Date } & \multirow[b]{2}{*}{ Progress Notes } \\
\hline & & $\begin{array}{l}\text { Original } \\
\text { Planned }\end{array}$ & $\begin{array}{l}\text { Revised } \\
\text { Planned }\end{array}$ & Actual & $\begin{array}{c}\text { Percent } \\
\text { Complete }\end{array}$ & \\
\hline 1 & Business Formation & $3 / 1 / 2004$ & $6 / 1 / 2004$ & $3 / 22 / 2004$ & $100 \%$ & Completed \\
\hline 2 & Design Optimization & 9/30/2004 & & $2 / 20 / 2004$ & $100 \%$ & Completed \\
\hline 3 & Prototype Development & $3 / 30 / 2004$ & & $3 / 30 / 2004$ & $100 \%$ & Completed \\
\hline 4 & Patent Development & $12 / 30 / 2003$ & & $10 / 30 / 2003$ & $100 \%$ & Completed \\
\hline 5 & Prototype Testing & $5 / 30 / 2004$ & & $5 / 30 / 2004$ & $100 \%$ & Completed \\
\hline 6 & Product Optimization & $8 / 1 / 2004$ & & $6 / 30 / 2004$ & $100 \%$ & Completed \\
\hline 7 & Business Development & $4 / 1 / 2005$ & & $6 / 30 / 2004$ & $100 \%$ & Completed \\
\hline 8 & Market Research & $8 / 3 / 2004$ & & $3 / 30 / 2004$ & $100 \%$ & Completed \\
\hline 9 & Report Submission & $4 / 1 / 2005$ & & $10 / 13 / 2004$ & $100 \%$ & Completed \\
\hline
\end{tabular}

\begin{tabular}{|c|c|c|c|c|c|c|c|}
\hline \multicolumn{8}{|c|}{$\begin{array}{c}\text { Appendix B } \\
\text { Final Spending Schedule }\end{array}$} \\
\hline \multicolumn{2}{|c|}{ Spending Schedule } & & \multicolumn{2}{|c|}{$\begin{array}{r}\text { Project Period: } \\
\text { Current Quarter: }\end{array}$} & \multicolumn{3}{|c|}{$\begin{array}{c}10 / 01 / 03 \text { to } 9 / 1 / 04 \\
4 / 1 / 04 \text { through } 6 / 30 / 04\end{array}$} \\
\hline \multirow{2}{*}{\multicolumn{2}{|c|}{ Task }} & \multirow{2}{*}{\multicolumn{2}{|c|}{$\begin{array}{l}\text { Approved } \\
\text { Budget }\end{array}$}} & \multicolumn{4}{|c|}{\begin{tabular}{|c|} 
Project Expenditures \\
\end{tabular}} \\
\hline & & & & \multicolumn{2}{|c|}{ This Quarter } & \multicolumn{2}{|c|}{$\begin{array}{c}\text { Cumulative to } \\
\text { Date }\end{array}$} \\
\hline 1 & Business Formation & $\$$ & 2,500 & & - & $\$$ & 2,500 \\
\hline 2 & Design Optimization & $\$$ & 45,000 & & - & $\$$ & 45,000 \\
\hline 3 & Prototype Development & $\$$ & 15,350 & & - & $\$$ & 15,350 \\
\hline 4 & Patent Development & $\$$ & 2,000 & & - & $\$$ & 2,000 \\
\hline 4 & Prototype Testing & $\$$ & 25,000 & & - & $\$$ & 25,000 \\
\hline 5 & Product Optimization & $\$$ & 50,000 & & - & $\$$ & 50,000 \\
\hline 6 & Business Development & $\$$ & 55,000 & & - & $\$$ & 55,000 \\
\hline 7 & Market Research & $\$$ & 11,000 & & - & $\$$ & 11,000 \\
\hline 8 & Report Submission & $\$$ & 750 & & 300 & $\$$ & 750 \\
\hline \multicolumn{2}{|c|}{ Total } & $\$$ & 206,600 & & 300 & $\$$ & 206,600 \\
\hline \multicolumn{2}{|c|}{ DOE Share } & $\$$ & 75,000 & $\$$ & - & $\$$ & 75,000 \\
\hline \multicolumn{2}{|c|}{ Cost Share } & $\$$ & 131,600 & $\$$ & 300 & $\$$ & 131,600 \\
\hline
\end{tabular}




\section{Appendix C \\ Final Cost Share Contributions}

\begin{tabular}{|c|c|c|c|c|c|c|}
\hline \multicolumn{7}{|c|}{ Cost Share Contributions } \\
\hline \multirow[b]{2}{*}{ Funding Source } & \multicolumn{2}{|c|}{ Approved Cost Share } & \multicolumn{2}{|c|}{ This Quarter } & \multicolumn{2}{|c|}{ Cumulative to Date } \\
\hline & Cash & In-Kind & Cash & In-Kind & Cash & In-Kind \\
\hline Freight Wing Incorporated & $\$ 97,540.00$ & & 300.00 & & $\$ 97,540.00$ & \\
\hline Fred Baehr & & $\$ 12,121.50$ & & & & $12,121.50$ \\
\hline Chris Leoniak & & $\$ 12,121.50$ & & & & $12,121.50$ \\
\hline Giles Frith & & $\$ 6,060.50$ & & & & $6,060.50$ \\
\hline Mike Graham & & $\$ 3,756.50$ & & & & $3,756.50$ \\
\hline Total & $\$ 97,540.00$ & $\$ 34,060.00$ & 300.00 & $\$$ & $\$ 97,540.00$ & $34,060.00$ \\
\hline & & Imulative Cos & t Share Cont & butions & $\$$ & $131,600.00$ \\
\hline
\end{tabular}




\section{Appendix D \\ Energy Savings Metrics}

\section{Discussion of Energy Savings:}

Freight Wing energy savings were experimentally derived during the course of the project. SAE/TMC J1321 type II fuel economy tests conducted by the Transportation Research Center (TRC) demonstrated a $7 \%$ reduction in the fuel consumption of a fully loaded semi truck. The TRC report is available by request and for download at freightwing.com

Our original fuel savings predictions were based on an entirely different product design that proved unacceptable to the industry due to high costs, maintenance issues, durability concerns, and weight (see section 2). It is however, unlikely that the original concept could have produced our predicted fuel savings of $12 \%$ to $15 \%$, as our estimations were based on claims made by similar projects that did not undergo standardized fuel economy tests and are likely exaggerated (see section 1.4 of our original proposal). Freight Wing's 7\% fuel reduction represents the highest published SAE/TMC J1321 test result for any aerodynamic trailer that we are aware of. The new product designs are also much cheaper to produce than our original concept, and thereby produce a better return on investment than we originally expected.

\section{Calculations}

One Unit of Current Technology: One tractor-trailer combination with a loaded van (box shaped) trailer.

According to the U.S. Department of Transportation, Federal Highway Administration, Highway statistics 2001 report, there were 2,154,000 combination trucks registered in the U.S., which traveled a total of 135,400 Million miles, at an average fuel economy of 5.3 miles per gallon. Note that there are more trailers registered than trucks $(4,864,350)$ because fleets typically employ more trailers to make loading/unloading operations more efficient.

The average truck therefore traveled:

$135,400,000,000$ miles $/ 215,400$ trucks $=62,860$ miles $/$ truck

And used:

$(62,860$ miles / truck $) /(5.3$ miles/gallon $)=11,860$ gallons of fuel per year

In energy terms:

11,860 gallons of fuel/year X 126,000 Btu/gallon = 1,494 Million Btu/year

One Unit of Proposed Technology: One tractor-trailer combination with a loaded van (box shaped) trailer, employing Freight Wing Products (the gap, belly and rear fairings).

Using figures from the previous calculations, the $7 \%$ fuel savings demonstrated by Freight Wing products in SAE standardized tests would lower and average trucks annual fuel consumption by: 
11,860 gallons/year $\times 7 \%=830$ gallons/year

Resulting in a total consumption of:

11,860 gallons/year -830 gallons/year $=11,030$ gallons/year

In energy terms:

11,030 gallons of fuel/year X 126,000 Btu/gallon $=1,390$ Million Btu/year

\section{Estimated Number of Units in 2010}

According to the Highway statistics 2001 report, there were 1,675,000 combination trucks registered in the U.S. in 1992 and 2,254,000 in 2001. Therefore, the U.S. combination truck population grew by $29 \%$ in 9 years. Assuming this trend continues, there will be:

$2,254,000$ trucks $+2,254,000$ trucks $X 29 \%=2,908,000$ combination trucks (units) in 2010

\section{Total Energy Savings}

Using figures from the previous calculations, each combination truck (unit) will save:

1,494 Million Btu/year - 1,390 Million Btu/year $=104$ Million Btu/year/unit

Multiplied by the estimated truck population in 2010:

104 Million Btu/year/unit * 2,980,000 units $=309,900,000,000,000$ Btu/year

\section{Existing Freight Wing products could potentially save the U.S. over 300 Trillion Btu's/year by 2010.}

\section{Energy Savings}

Metrics

\begin{tabular}{|c|c|c|c|c|c|}
\hline & A & B & C=A-B & D & E=CxD \\
\cline { 2 - 6 } $\begin{array}{c}\text { Type of } \\
\text { Energy } \\
\text { Used }\end{array}$ & $\begin{array}{c}\text { Current } \\
\text { Technology } \\
\text { (Btu / yr / unit) }\end{array}$ & $\begin{array}{c}\text { Proposed } \\
\text { Technology } \\
\text { (Btu / yr / unit) }\end{array}$ & $\begin{array}{c}\text { Energy } \\
\text { Savings } \\
\text { (Btu / yr / unit) }\end{array}$ & $\begin{array}{c}\text { Estimated } \\
\text { Number of Units } \\
\text { in U.S. by 2010 } \\
\text { (units) }\end{array}$ & $\begin{array}{c}\text { Energy } \\
\text { Savings by } \\
2010 \\
\text { (Btu / yr) }\end{array}$ \\
\hline $\begin{array}{c}\text { Oil / } \\
\text { Gasoline }\end{array}$ & 1,494 Million & 1,390 Million & 104 Million & 2,980 Thousand & 309.9 Trillion \\
\hline
\end{tabular}

